\title{
Further Insights on the Assembly of Acylaminopyridine-based [2]Rotaxanes
}

Julio A. Rodriguez-Martinez, Alberto Martinez-Cuezva,* Mateo Alajarin, Jose Berna*

Departamento de Química Orgánica, Facultad de Química, Regional Campus of International Excellence “Campus Mare Nostrum”, Universidad de Murcia, 30100, Murcia, Spain

e-mail:amcuezva@um.es, ppberna@um.es

Abstract: The synthesis of novel hydrogen-bonded [2]rotaxanes employing an acylaminopyridine-containing thread as template is described. The electronic nature of the starting aroyl chloride employed as macrocycle precursor plays an important role in the formation of the hydrogen-bonding interactions of the supramolecular precursors of the interlocked architectures. Indeed, whereas the preparation of the rotaxane employing isophthaloyl chloride and the pyridine-based template was unfeasible, the introduction of nitro substituent at the position of the same precursor allowed the formation of the target amide-based rotaxane.

Keywords: supramolecular chemistry, interlocked molecules, acylaminopyridine, template synthesis, hydrogen-bonding interactions

\section{INTRODUCTION}

Controlling motion in interlocked molecular architectures is an important research topic for the scientific community ${ }^{1,2}$ and, mainly, for researchers interested on the modelization of the biological machinery and the development of stimuli-responsive molecular devices. ${ }^{3-5}$ In this context, different templates have been used not only to maximize the yield of the assembly of the interlocked compound, but also, to incorporate an adjustable element able to participate in the taming of the Brownian movement inherent to these molecules. We recently reported the use of the di(acylamino)pyridine (DAP) moiety as an active template in the synthesis of hydrogenbonded [2]rotaxanes (Scheme 1). ${ }^{6}$ Moreover the control of the traslational motion of the macrocycle along the axle could be achieved, among other external stimuli, by an unprecedented molecular recognition event with small molecules, such as barbiturates or thymine derivatives (acceptor-donor-acceptor arrays). Interestingly, in the solid state the tetralactam macrocycle interacts with two of the three accessible hydrogen-bonding (HB) acceptors of the thread: one of the two available oxygen atoms of the amides and the nitrogen atom of the pyridine ring.

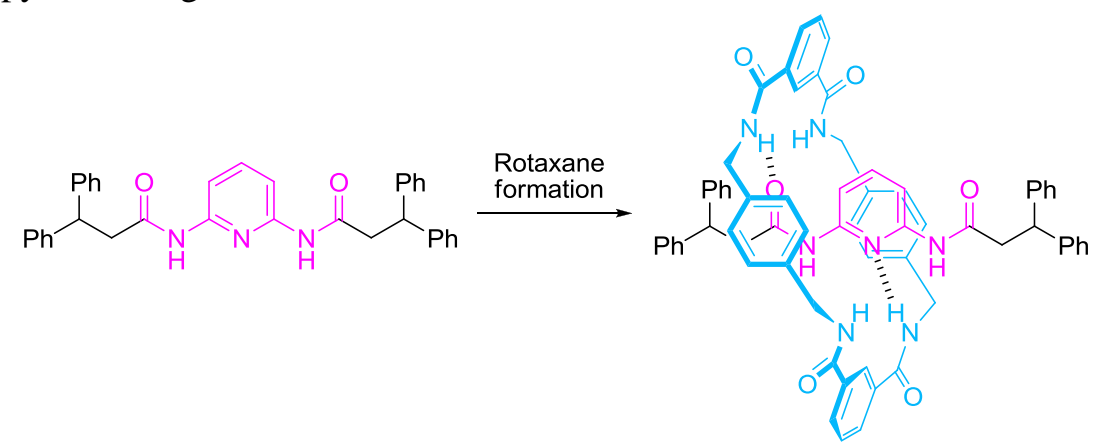

Scheme 1. Synthesis of a DAP-based [2]rotaxane. Thread-macrocycle HB pattern observed in the solid stated is displayed with dashed lines. 
Having in mind these pioneer results we envisaged that an acylaminopyridine (AAP) moiety, with only two HB acceptors, could effectively act as template for the formation of polyamidebased rotaxanes (Scheme 2). Thus the traslational motion of the tetralactam macrocycle in derived molecular shuttles containing the AAP binding site could be potentially driven by the action of different external stimuli, such as $\mathrm{pH}$ variations, or by the addition of small molecules with a complementary HB pattern (Acceptor-Donor arrays).

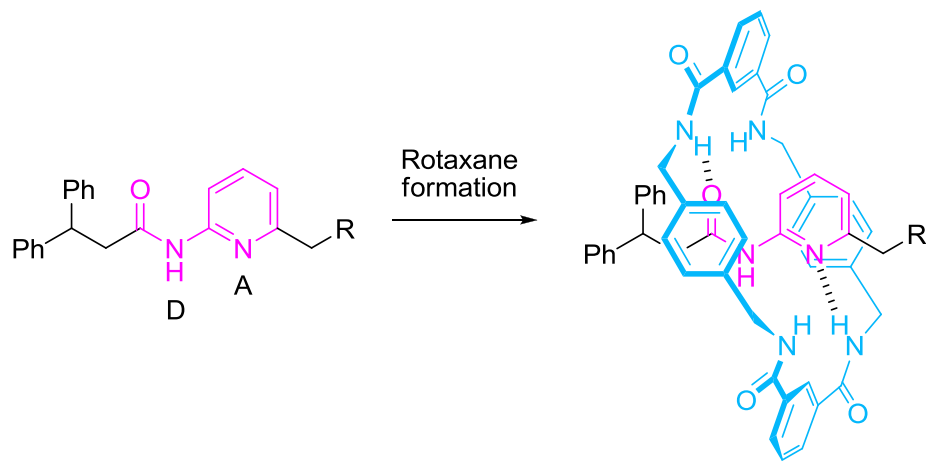

Scheme 2. Designed synthesis of a [2] rotaxane having an AAP binding site. R: alkyl group; D: HB donor; A: HB acceptor.

\section{EXPERIMENTAL}

\section{Preparation of the acylaminopyridine-containing thread 3}

The synthesis of the thread $\mathbf{3}$, having an acylaminopyridine-based binding site, was achieved following the synthetic route despicted in Scheme 3.

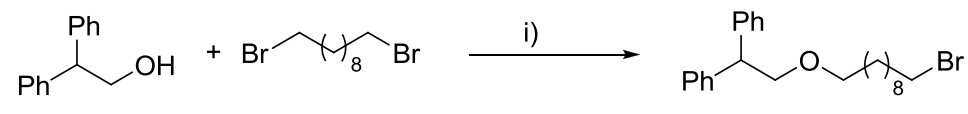

1

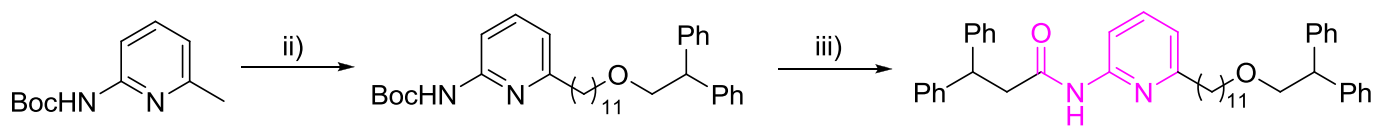

2

3

Scheme 3. Synthesis of thread 3. Reaction conditions: i) $\mathrm{NaOH} / \mathrm{H}_{2} \mathrm{O}, \mathrm{TBAB}, \mathrm{rt}, 7 \mathrm{~h}, 85 \%$; ii) $n$ BuLi, THF, $-78^{\circ} \mathrm{C}, 1 \mathrm{~h}, \mathrm{~N}_{2}$ atm; then $1,-78^{\circ} \mathrm{C}, 1 \mathrm{~h}, 61 \%$; iii) a) TFA, $\mathrm{CH}_{2} \mathrm{Cl}_{2}, \mathrm{rt}, 18 \mathrm{~h}$; b) 3,3diphenylpropionic acid, EDCI, $\mathrm{HOBt}, \mathrm{Et}_{3} \mathrm{~N}, \mathrm{CH}_{2} \mathrm{Cl}_{2}, 0{ }^{\circ} \mathrm{C}, 48 \mathrm{~h}, 47 \%$. EDCI: 1-ethyl-3-(3dimethylaminopropyl)carbodiimide; HOBt: hydroxybenzotriazole; TBAB: tetrabutylammonium bromide; THF: tetrahydrofuran; TFA: trifluoroacetic acid.

\section{Preparation of fragment 1}

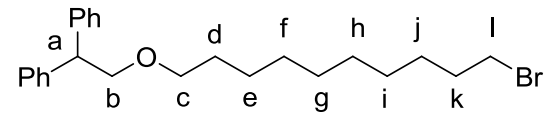

To a mixture of 2,2-diphenylethanol (5.0 g, $25.2 \mathrm{mmol})$ and 1,10-dibromodecane (22.7 g, 17.0 $\mathrm{mL}, 75.6 \mathrm{mmol})$ an aqueous solution of $\mathrm{NaOH}(50 \% \mathrm{v} / \mathrm{v}, 12.5 \mathrm{~mL})$ and $\mathrm{TBAB}(0.33 \mathrm{~g}, 1.0$ $\mathrm{mmol}$ ) were added. The reaction mixture was stirred at room temperature for $7 \mathrm{~h}$. After this time $\mathrm{H}_{2} \mathrm{O}(125 \mathrm{~mL})$ was added and the mixture was extracted with $\mathrm{Et}_{2} \mathrm{O}(3 \times 125 \mathrm{~mL})$. The combined organic phases were dried over magnesium sulfate and filtered. The solvent was removed under 
reduced pressure and the resulting residue was purified by silica gel column chromatography using a mixture of hexanes/diethyl ether (95:5) as eluent. NOTE: a minor amount of 1,10bis(2,2-diphenylethoxy)decane was also obtained.

Fragment 1: 9.62 g, 92\% yield; colourless oil; IR (Nujol): 704 (vs), 741 (s), 1128 (vs), 1447 (s), 1496 (s), 1605 (w), 2855 (vs), 2930 (vs), 3024 (m), 3062 (m); ${ }^{1} \mathrm{H}$ NMR (300 MHz, 298 K, $\left.\mathrm{CDCl}_{3}\right): \delta(\mathrm{ppm}) 7.33-7.15(\mathrm{~m}, 10 \mathrm{H}, \mathrm{Ph}), 4.30\left(\mathrm{t}, J=7.3 \mathrm{~Hz}, 1 \mathrm{H}, \mathrm{H}_{\mathrm{a}}\right), 3.95(\mathrm{~d}, J=7.3 \mathrm{~Hz}, 2 \mathrm{H}$, $\left.\mathrm{H}_{\mathrm{b}}\right), 3.46\left(\mathrm{t}, J=6.6 \mathrm{~Hz}, 2 \mathrm{H}, \mathrm{H}_{\mathrm{c}}\right), 3.41\left(\mathrm{t}, J=6.9 \mathrm{~Hz}, 2 \mathrm{H}, \mathrm{H}_{\mathrm{l}}\right), 1.92-1.78\left(\mathrm{~m}, 2 \mathrm{H}, \mathrm{H}_{\mathrm{k}}\right), 1.56-$ $1.52\left(\mathrm{~m}, 2 \mathrm{H}, \mathrm{H}_{\mathrm{d}}\right), 1.45-1.40\left(\mathrm{~m}, 2 \mathrm{H}, \mathrm{H}_{\mathrm{j}}\right), 1.29-1.05\left(\mathrm{~m}, 10 \mathrm{H}, \mathrm{H}_{\mathrm{e}-\mathrm{i}}\right) ;{ }^{13} \mathrm{C}$ NMR $(75 \mathrm{MHz}, 298$ $\left.\mathrm{K}, \mathrm{CDCl}_{3}\right): \delta(\mathrm{ppm}) 142.3(\mathrm{C}), 128.3,126.3,73.9,71.1,50.9(\mathrm{CH}), 34.0,32.8,29.4,29.4,29.3$, 28.7, 28.1, 26.0; HRMS (ESI) calcd for $\mathrm{C}_{24} \mathrm{H}_{37} \mathrm{NO}\left[\mathrm{M}+\mathrm{NH}_{4}\right]^{+} 434.2059$, found 434.2060.

\section{Preparation of fragment 2}

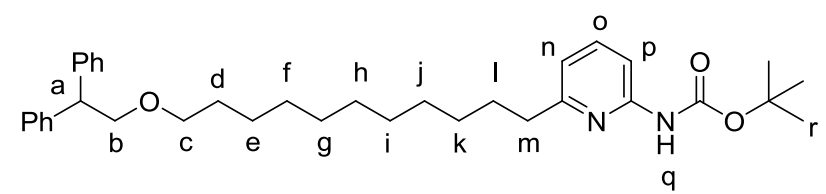

To a solution of 2-(tert-butoxycarbonylamino)-6-methylpyridine (1,0 g, $4.8 \mathrm{mmol})$ in anhydrous THF $(7.7 \mathrm{~mL})$ at $-78{ }^{\circ} \mathrm{C}$ under $\mathrm{N}_{2}$ atmosphere, a solution of $n$-BuLi (1M in hexane, $3.84 \mathrm{~mL}$, $9.60 \mathrm{mmol}$ ) was added dropwise during $15 \mathrm{~min}$. After this time the solution was allowed to warm to room temperature and was stirred for another hour. The mixture was again cooled to $78^{\circ} \mathrm{C}$ and a solution of $\mathbf{1}(1.60 \mathrm{~g}, 3.84 \mathrm{mmol})$ in anhydrous THF $(7.7 \mathrm{~mL})$ was added dropwise. The reaction mixture was stirred from $-78^{\circ} \mathrm{C}$ to room temperature for 24 hours. After this time cold $\mathrm{H}_{2} \mathrm{O}(50 \mathrm{~mL})$ was added and the mixture was extracted with $\mathrm{CH}_{2} \mathrm{Cl}_{2}(3 \times 30 \mathrm{~mL})$. The combined organic phases were dried over magnesium sulfate and filtered. The solvent was removed under reduced pressure and the resulting residue was purified by silica gel column chromatography using a mixture of hexanes/diethyl ether (50:50) as eluent.

Fragment 2: 2.57 g, 61\% yield; yellow oil; IR (Nujol): 653 (s), 730 (s), 898 (vs), 1167 (vs), 1456 (vs), 1735 (s), 2249 (w), 2860 (s), 2924 (s), 3418 (w); ${ }^{1} \mathrm{H}$ NMR (400 MHz, 298 K, CDCl3): $\delta(\mathrm{ppm}) 7.71\left(\mathrm{~d}, J=8.3 \mathrm{~Hz}, 1 \mathrm{H}, \mathrm{H}_{\mathrm{p}}\right), 7.55-7.52\left(\mathrm{~m}, 1 \mathrm{H}, \mathrm{H}_{\mathrm{o}}\right), 7.33-7.10(\mathrm{~m}, 10 \mathrm{H}, \mathrm{Ph})$, $6.78\left(\mathrm{~d}, J=7.4 \mathrm{~Hz}, 1 \mathrm{H}, \mathrm{H}_{\mathrm{n}}\right), 4.27\left(\mathrm{t}, J=7.3 \mathrm{~Hz}, 1 \mathrm{H}, \mathrm{H}_{\mathrm{a}}\right), 3.93\left(\mathrm{~d}, J=7.3 \mathrm{~Hz}, 2 \mathrm{H}, \mathrm{H}_{\mathrm{b}}\right), 3.44(\mathrm{t}, J$ $\left.=6.6 \mathrm{~Hz}, 2 \mathrm{H}, \mathrm{H}_{\mathrm{c}}\right), 2.63\left(\mathrm{~m}, 2 \mathrm{H}, \mathrm{H}_{\mathrm{m}}\right), 1.58-1.43\left(\mathrm{~m}, 13 \mathrm{H}, \mathrm{H}_{\mathrm{d}+1+\mathrm{r}}\right), 1.38-1.16\left(\mathrm{~m}, 14 \mathrm{H}, \mathrm{H}_{\mathrm{e}-\mathrm{k}}\right)$; ${ }^{13} \mathrm{C}$ NMR $\left(100 \mathrm{MHz}, 298 \mathrm{~K}, \mathrm{CDCl}_{3}\right): \delta(\mathrm{ppm})=160.9(\mathrm{CO}), 152.4(\mathrm{C}), 151.1(\mathrm{C}), 142.4(\mathrm{C})$, 138.3, 128.3, 128.3, 126.3, 117.3, 109.1, $80.6(\mathrm{C}), 74.0,71.2,51.0(\mathrm{CH}), 38.0,29.7,29.5,29.4$, 29.3, 29.3, $28.2\left(\mathrm{CH}_{3}\right), 26.0$; HRMS (ESI) calcd for $\mathrm{C}_{35} \mathrm{H}_{49} \mathrm{~N}_{2} \mathrm{O}_{3}[\mathrm{M}+\mathrm{H}]^{+}$545.3743, found 545.3740 .

\section{Preparation of thread 3}

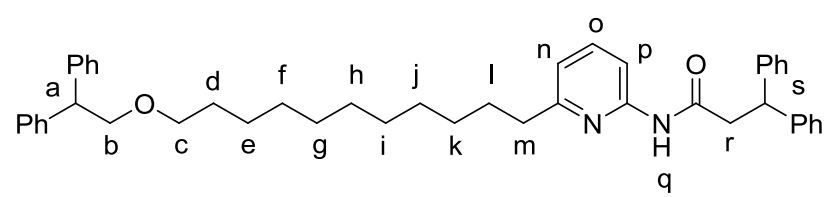

To a solution of carbamate $2(1.04 \mathrm{~g}, 1.91 \mathrm{mmol})$ in anhydrous $\mathrm{CH}_{2} \mathrm{Cl}_{2}(12 \mathrm{~mL})$ was added TFA $(1.47 \mathrm{ml}, 19.1 \mathrm{mmol})$. The reaction mixture was stirred at room temperature for $24 \mathrm{~h}$. After this time the solvent was removed under reduced pressure. The resulting salt $\mathbf{S 1}$ was dried under high vacuum for removing the excess of TFA and was used without further purification (S1, colourless oil, $0.85 \mathrm{~g}, 99 \%$ ). 
To a suspension of 3,3-diphenylpropionic acid $(0.26 \mathrm{~g}, 1.14 \mathrm{mmol})$ in anhydrous $\mathrm{CH}_{2} \mathrm{Cl}_{2}$ (21 $\mathrm{mL})$ at $0{ }^{\circ} \mathrm{C}$ under $\mathrm{N}_{2}$ atmosphere, EDCI $(0.25 \mathrm{~g}, 1.33 \mathrm{mmol})$, $\mathrm{HOBt}(0.18 \mathrm{~g}, 1.33 \mathrm{mmol})$ and triethylamine $(0.8 \mathrm{~mL}, 5.7 \mathrm{mmol})$ were added. The reaction mixture was stirred for $15 \mathrm{~min}$ and then was allowed to warm to room temperature. At this point the salt $\mathbf{S 1}(0.85 \mathrm{~g}, 1.91 \mathrm{mmol})$ dissolved in anhydrous $\mathrm{CH}_{2} \mathrm{Cl}_{2}(6 \mathrm{~mL})$ was added and the reaction mixture was stirred for $48 \mathrm{~h}$. After this time the organic mixture was washed with a saturated aqueous solution of $\mathrm{NaHCO}_{3}$ $(20 \mathrm{~mL})$ and brine $(20 \mathrm{~mL})$. The organic phase was dried over magnesium sulfate and filtered. The solvent was removed under reduced pressure and the resulting residue was purified by silica gel column chromatography using a mixture of $\mathrm{CHCl}_{3} / \mathrm{MeOH}(98: 2)$ as eluent.

Thread 3: 0.28 g, 47\% yield; yellow oil; IR (Nujol): 650 (s), 1103 (m), 1168 (vs), 1580 (s), 1738 (s), 2248 (w), 2860 (s), 2924 (vs), 3418 (w); ${ }^{1} \mathrm{H}$ NMR (400 MHz, $298 \mathrm{~K}, \mathrm{CDCl}_{3}$ ): $\delta$ (ppm) $7.36\left(\mathrm{dd}, J=8.5,7.3 \mathrm{~Hz}, 1 \mathrm{H}, \mathrm{H}_{\mathrm{o}}\right), 7.33-7.11(\mathrm{~m}, 20 \mathrm{H}, \mathrm{Ph}), 6.38\left(\mathrm{~d}, J=7.3 \mathrm{~Hz}, 1 \mathrm{H}, \mathrm{H}_{\mathrm{p}}\right), 6.28$ $\left(\mathrm{d}, J=8.5 \mathrm{~Hz}, 1 \mathrm{H}, \mathrm{H}_{\mathrm{n}}\right), 4.62\left(\mathrm{t}, J=7.9 \mathrm{~Hz}, 1 \mathrm{H}, \mathrm{H}_{\mathrm{r}}\right), 4.30\left(\mathrm{t}, J=7.3 \mathrm{~Hz}, 1 \mathrm{H}, \mathrm{H}_{\mathrm{a}}\right), 3.96(\mathrm{~d}, J=7.3$ $\left.\mathrm{Hz}, 2 \mathrm{H}, \mathrm{H}_{\mathrm{b}}\right), 3.46\left(\mathrm{t}, J=6.6 \mathrm{~Hz}, 2 \mathrm{H}, \mathrm{H}_{\mathrm{c}}\right), 3.07\left(\mathrm{~d}, J=7.9 \mathrm{~Hz}, 2 \mathrm{H}, \mathrm{H}_{\mathrm{s}}\right), 2.64-2.54\left(\mathrm{~m}, 2 \mathrm{H}, \mathrm{H}_{\mathrm{m}}\right)$, $1.66-1.49\left(\mathrm{~m}, 4 \mathrm{H}, \mathrm{H}_{\mathrm{d}+1}\right), 1.35-1.20\left(\mathrm{~m}, 14 \mathrm{H}, \mathrm{H}_{\mathrm{e}-\mathrm{k}}\right) ;{ }^{13} \mathrm{C} \mathrm{NMR}\left(100 \mathrm{MHz}, 298 \mathrm{~K}, \mathrm{CDCl}_{3}\right): \delta$ (ppm) $177.8(\mathrm{CO}), 157.0(\mathrm{C}), 156.3(\mathrm{C}), 144.6(\mathrm{C}), 142.3(\mathrm{C}), 140.6,128.3,128.3,127.8,126.3$, 126.1, 111.0, 108.2, 73.9, 71.2, $50.9(\mathrm{CH}), 47.4(\mathrm{CH}), 42.4,34.6,29.6(x 2), 29.5,29.5,29.4$ (x2), 29.3, 29.1, 26.0; HRMS (ESI) calcd for $\mathrm{C}_{45} \mathrm{H}_{53} \mathrm{~N}_{2} \mathrm{O}_{2}[\mathrm{M}+\mathrm{H}]^{+}$653.4107, found 653.4115.

\section{General procedure for the synthesis of polyamide-based rotaxanes.}

The thread 3 (1 mmol) and $\mathrm{Et}_{3} \mathrm{~N}$ (24 equiv) in anhydrous $\mathrm{CHCl}_{3}(300 \mathrm{~mL})$ were stirred vigorously whilst solutions of $p$-xylylenediamine (8 equiv) in anhydrous $\mathrm{CHCl}_{3}(20 \mathrm{~mL})$ and the corresponding acid dichloride (8 equiv) in anhydrous $\mathrm{CHCl}_{3}(20 \mathrm{~mL})$ were simultaneously added over a period of $5 \mathrm{~h}$ using motor-driven syringe pumps. After being stirred for $4 \mathrm{~h}$ the resulting suspension was filtered through a Celite pad, washed with water $(2 \times 50 \mathrm{~mL})$, a saturated solution of $\mathrm{NaHCO}_{3}(2 \times 50 \mathrm{~mL})$ and brine $(2 \times 50 \mathrm{~mL})$. The organic phase was dried over $\mathrm{MgSO}_{4}$ and the solvent was removed under reduced pressure. The resulting residue was analyzed by high-resolution mass spectrometry trying to find the desired molecular ion peak in the mass spectrum.

\section{RESULTS AND DISCUSSION}

Having in mind the reported studies carried out for the synthesis of hydrogen-bonded [2]rotaxanes employing DAP-based templates, ${ }^{6}$ we thought in the possibility of using a thread containing an AAP function as binding site for the preparation of relative interlocked architectures. For this purpose we planned the synthesis of thread 3, bearing the AAP binding site attached to an alkyl chain, which improves the solubility of the target compound in organic solvents. Also, bulky substituents will be incorporated at both ends of the linear component for maintaining the mechanical bond between the two interlocked subcomponents.

The synthesis of thread $\mathbf{3}$ started with the reaction of the commercially available 2-(tertbutoxycarbonylamino)-6-methylpyridine with $n$-BuLi, under inert atmosphere and low temperature, generating the lithiated intermediate. The addition of the bromide $\mathbf{1}$, prepared following known procedures, ${ }^{7}$ to the reaction media afforded the carbamate $\mathbf{2}$ in $61 \%$ yield after purification (Scheme 4). 

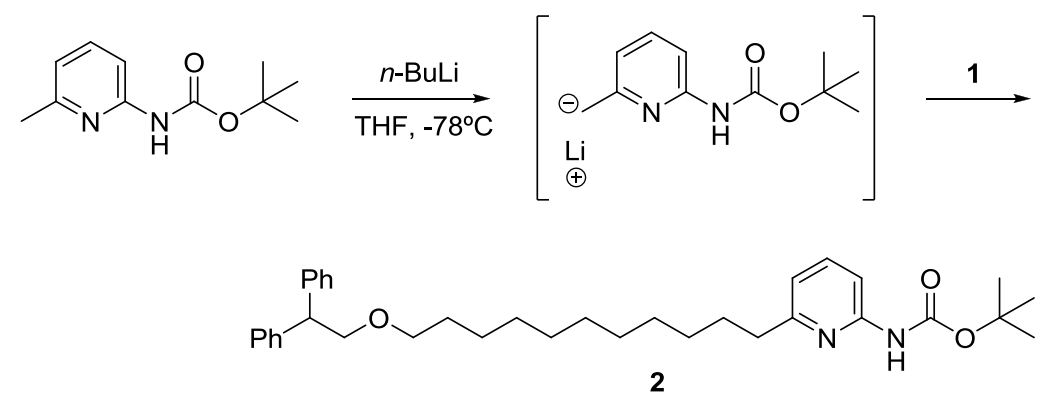

Scheme 4. Synthesis of carbamate 2.

The carbamate $\mathbf{2}$ was deprotected by treatment with TFA. After solvent removal, the corresponding intermediate salt S1 was quantitatively obtained and used without further purification (Scheme 5). The final coupling reaction between $\mathbf{S 1}$ and 3,3-diphenylpropionic acid in the presence of EDCI and HOBt provided the desired thread 3 in $47 \%$ yield.

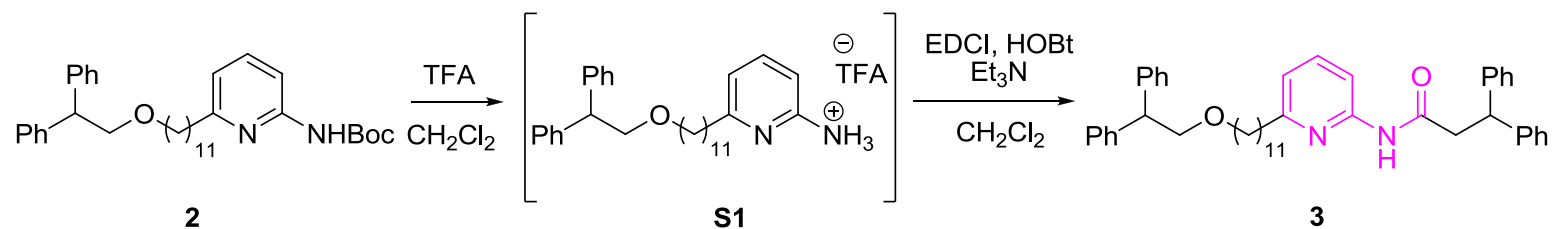

Scheme 5. Synthesis of thread 3.

The next step was to use the thread $\mathbf{3}$ as template for the synthesis of hydrogen-bonded rotaxanes through the well-known five-component clipping reaction with $p$-xylylenediamine and isophthaloyl chloride. Unfortunately the mass peak of the expected rotaxane 4 was not detected in the reaction mixture by HRMS (Scheme 6). This result points out that the AAP moiety is ineffective as a template in the formation of this type of hydrogen-bonded rotaxanes.

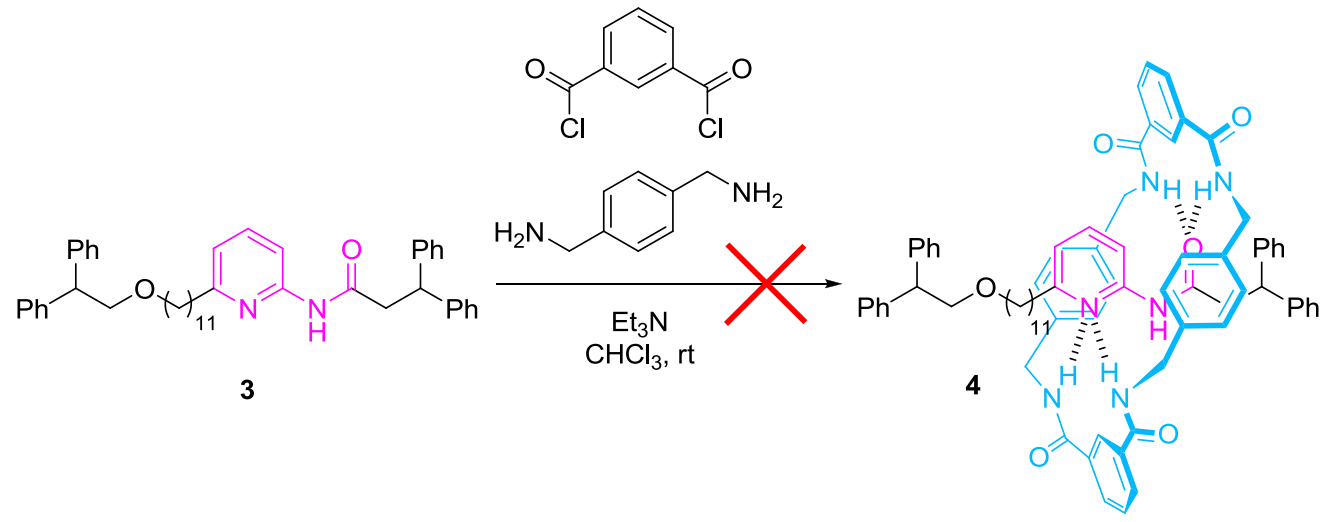

Scheme 6. Unsuccessful attempt for the preparation of rotaxane 4.

It is known that the presence of electron withdrawing groups at the position 5 of the isophthaloyl fragment of the tetralactam macrocycle enhances the hydrogen-bonding donating character $^{8,9}$ of the amide hydrogen atoms. Thus we envisaged that the employment of the 5nitroisophthaloyl dichloride as starting material could strengthen the hydrogen-bonding interactions between the template $\mathbf{3}$ and the lineal amide-based intermediate, stabilizing them in the proper spatial conformation where the amidation reaction which forms the final interlocked macrocycle could satisfactorily happen. ${ }^{10}$ Following this idea we carried out the corresponding five-component clipping reaction employing $p$-xylylenediamine and 5-nitroisophthaloyl chloride in the presence of thread $\mathbf{3}$ (Scheme 7). Interestingly traces of the expected rotaxane 5 
were observed. A fussy study of the reaction crude by high-resolution mass spectrometry allowed us to confirm the formation of the desired compound $\mathbf{5}$ as a minor product (Figure 1).

a)

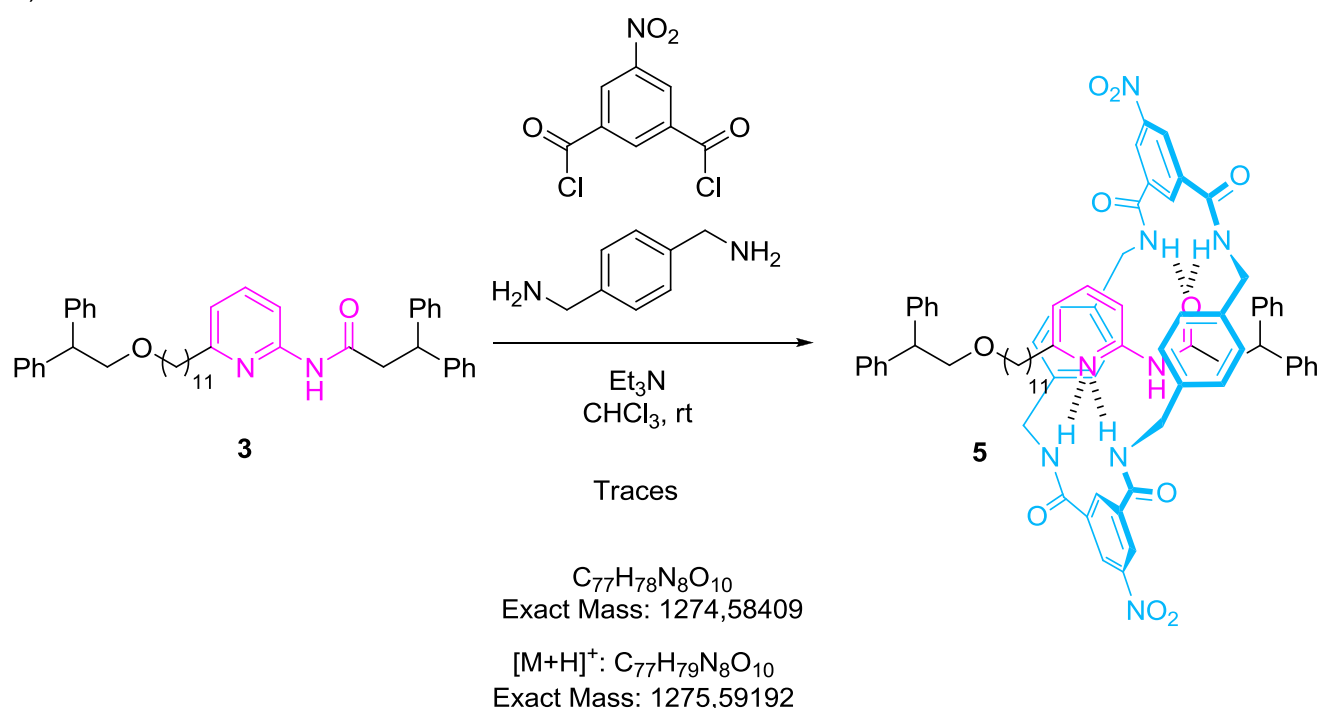

b)

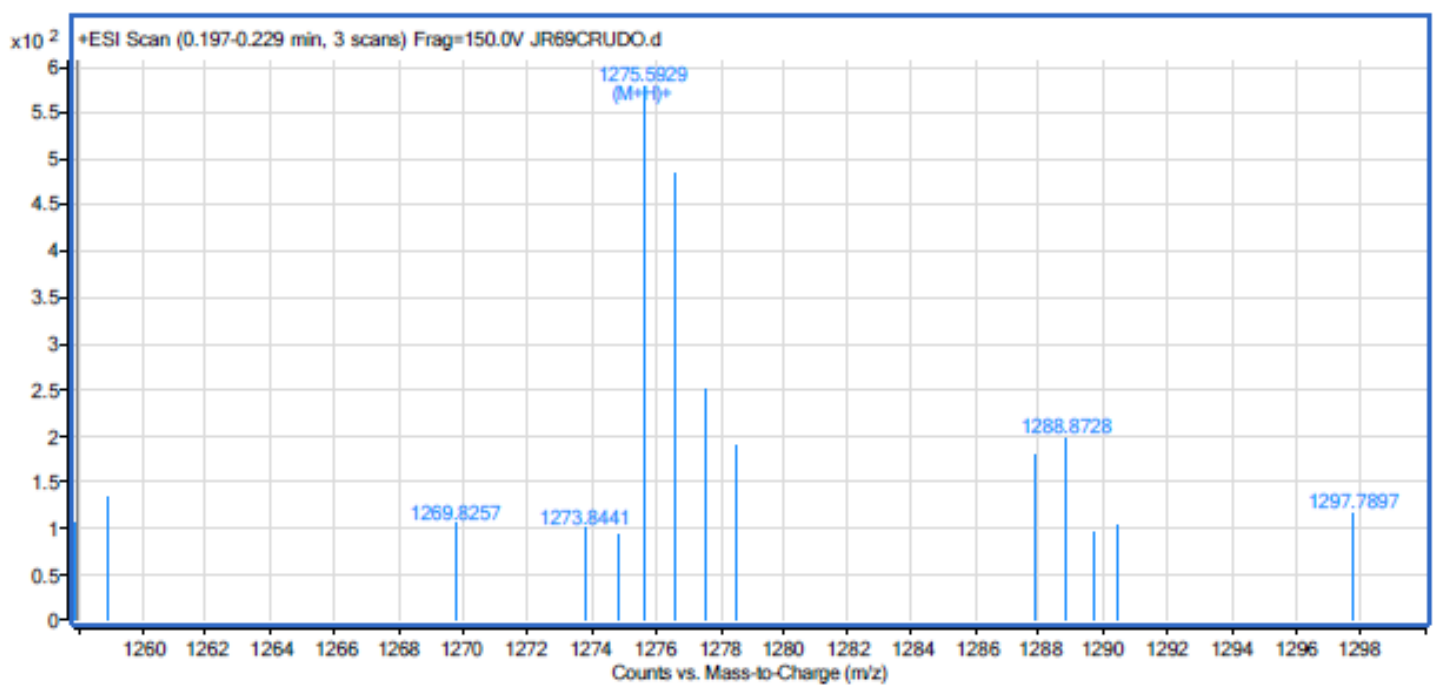

Scheme 7. a) Synthesis of the [2]rotaxane 5; b) HRMS (ESI+) spectrum for rotaxane $\mathbf{5}$.

\section{CONCLUSIONS}

Our synthetic efforts towards novel acylaminopyridine-based [2] rotaxanes through a fivecomponent clipping reaction are described. The electron withdrawing effect of the nitro groups at the position 5 of the isophthalic moiety of the tetralactam macrocycle, which enhance the acidity of the amide hydrogen atoms, allowed the preparation of traces of the target molecule, which was identified by high-resolution mass spectrometry. The second acylamino group, present in the related di(acylamino)pyridine functionality, seems to be crucial for the stabilization of the corresponding intermediates and the suitable final assembly of the interlocked structure. Nevertheless, these results open the door to the synthesis of this type of interlocked molecules, containing an acylaminopyridine function as binding site, due to the multiple possibilities of tuning the starting isophthalic acid derivatives. 


\section{ACKNOWLEDGEMENTS}

We gratefully acknowledge the MINECO (CTQ2014-56887-P) and Fundacion Seneca-CARM (Project 19240/PI/14) for the financial support. A.M.-C. thanks the Marie Curie COFUND and U-IMPACT programs (Grant Agreement 267143) and the MINECO (Contract No. FPDI-201316623) for the postdoctoral contracts.

\section{REFERENCES}

[1] J. F. Stoddart, Chem. Soc. Rev., 2009, 38, 1802.

[2] V. Balzani, A. Credi, M. Venturi, From Non-Covalent Assemblies to Molecular Machines, 2011, 159 .

[3] a) E. R. Kay, D. A. Leigh, F. Zerbetto, Angew. Chem. Int. Ed., 2007, 46, 72; b) E. R. Kay, D. A. Leigh, Angew. Chem. Int. Ed., 2015, 54, 10080.

[4] S. Erbas-Cakmak, D. A. Leigh, C. T. McTernan, A. L. Nussbaumer, Chem. Rev., 2015, 115, 10081.

[5] A. Martinez-Cuezva, S. Valero-Moya, M. Alajarin, J. Berna, Chem. Commun., 2015, 51, 14501.

[6] a) A. Martinez-Cuezva, J. Berna, R.-A. Orenes, A. Pastor, M. Alajarin, Angew. Chem. Int. Ed. 2014, 53, 6762; b) A. Martinez-Cuezva, A. Pastor, G. Cioncoloni, R.-A. Orenes, M. Alajarin, M. D. Symes, J. Berna, Chem. Sci. 2015, 6, 3087.

[7] P. A. Procopiou, V. J. Barrett, K. Biggadike, P. R. Butchers, A. Craven, A. J. Ford, S. B. Guntrip, D. S. Holmes, S. C. Hughes, A. E. Jones, B. E. Looker, P. J. Mutch, M. Ruston, D. Needham, C. E. Smith, J. Med. Chem. 2014, 57, 159.

[8] a) S.-Y. Chang, H. S. Kim, K.-J. Chang, K.-S. Jeong, Org. Lett. 2004, 6, 181; b) J. Berna, M. Alajarin, J. S. Martinez-Espin, L. Buriol, A. P. M. Martins, R.-A. Orenes, Chem. Commun. 2012, 48, 5677.

[9] A. Martinez-Cuezva, L. V. Rodrigues, C. Navarro, F. Carro-Guillen, L. Buriol, C. P. Frizzo, M. A. P. Martins, M. Alajarin, J. Berna, J. Org. Chem., 2015, DOI: 10.1021/acs.joc.5b01651

[10] D. A. Leigh, A. Murphy, J. P. Smart, A. M. Slawin, Angew. Chem. Int. Ed. Engl. 1997, 1, 728. 